\title{
Cloning and Characterization of a Biotic- Stress-Inducible Glutathione Transferase from Phaseolus vulgaris
}

\section{Evangelia Chronopoulou, Panagiotis Madesis, Athanasios Tsaftaris \& Nikolaos E. Labrou}

Applied Biochemistry and Biotechnology

Part A: Enzyme Engineering and Biotechnology

ISSN 0273-2289

Appl Biochem Biotechnol

DOI 10.1007/s12010-013-0509-3

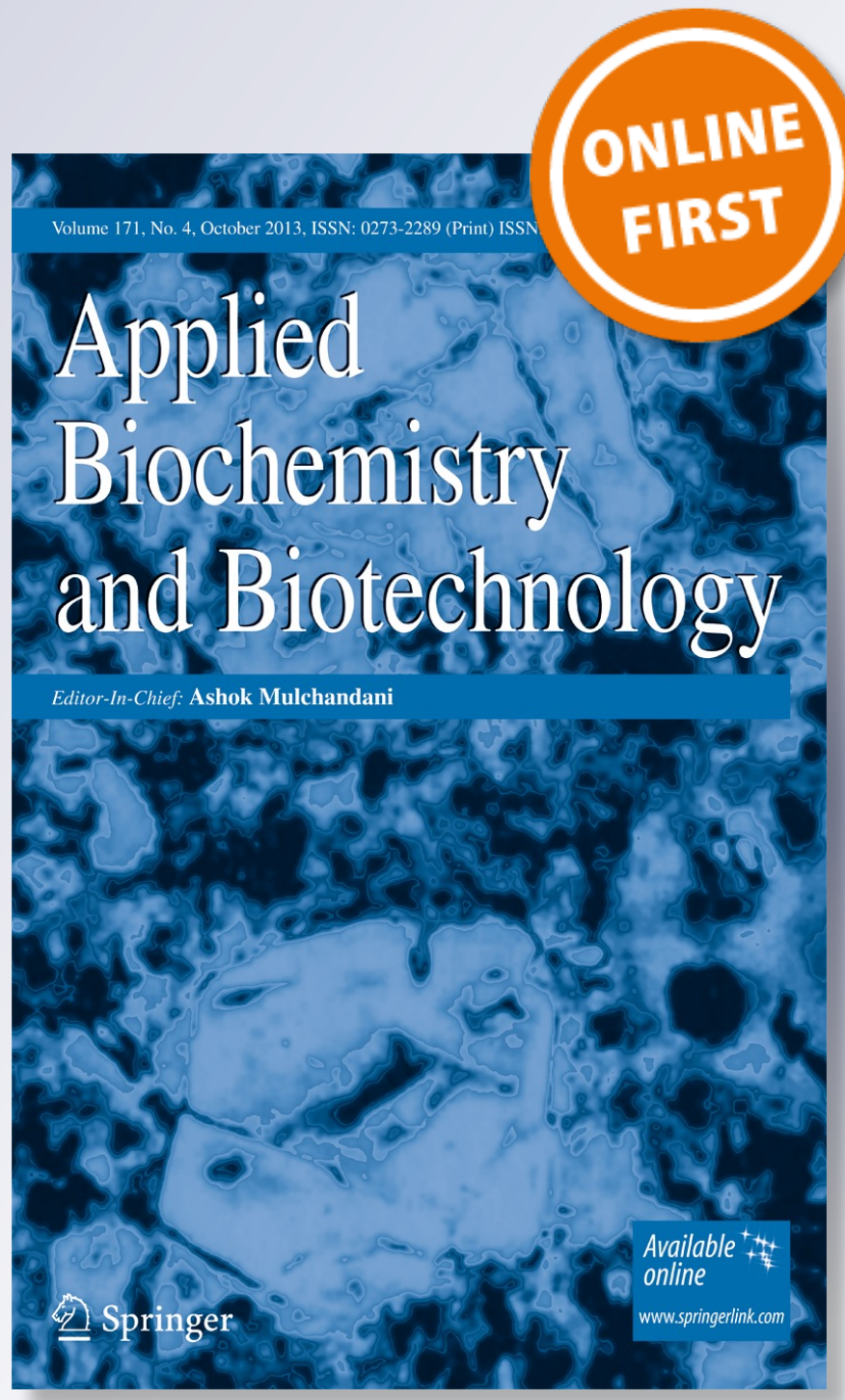

囪 Springer 
Your article is protected by copyright and all rights are held exclusively by Springer Science +Business Media New York. This e-offprint is for personal use only and shall not be selfarchived in electronic repositories. If you wish to self-archive your article, please use the accepted manuscript version for posting on your own website. You may further deposit the accepted manuscript version in any repository, provided it is only made publicly available 12 months after official publication or later and provided acknowledgement is given to the original source of publication and a link is inserted to the published article on Springer's website. The link must be accompanied by the following text: "The final publication is available at link.springer.com". 


\title{
Cloning and Characterization of a Biotic-Stress-Inducible Glutathione Transferase from Phaseolus vulgaris
}

\author{
Evangelia Chronopoulou • Panagiotis Madesis • Athanasios Tsaftaris • \\ Nikolaos E. Labrou
}

Received: 17 April 2013 / Accepted: 4 September 2013

(C) Springer Science+Business Media New York 2013

\begin{abstract}
Glutathione transferases (GSTs, EC 2.5.1.18) are ubiquitous proteins in plants that play important roles in stress tolerance and in the detoxification of toxic chemicals and metabolites. In this study, we systematically examined the catalytic diversification of a GST isoenzyme from Phaseolus vulgaris ( $P v \mathrm{GST}$ ) which is induced under biotic stress treatment (Uromyces appendiculatus infection). The full-length cDNA of this GST isoenzyme (termed PvGSTU3-3) with complete open reading frame, was isolated using RACE-RT and showed that the deduced amino acid sequence shares high homology with the tau class plant GSTs. PvGSTU3-3 catalyzes several different reactions and exhibits wide substrate specificity. Of particular importance is the finding that the enzyme shows high antioxidant catalytic function and acts as hydroperoxidase, thioltransferase, and dehydroascorbate reductase. In addition, its $K_{\mathrm{m}}$ for GSH is about five to ten times lower compared to other plant GSTs, suggesting that $P v \mathrm{GSTU} 3-3$ is able to perform efficient catalysis under conditions where the concentration of reduced glutathione is low (e.g., oxidative stress). Its ability to conjugate GSH with isothiocyanates may provide an additional role for this enzyme to act as a regulator of the released isothiocyanates from glucosinolates as a response of biotic stress. Molecular modeling showed that $P v$ GSTU3-3 shares the same overall fold and structural organization with other plant cytosolic GSTs, with major differences at their hydrophobic binding sites (H-sites) and some differences at the level of C-terminal domain and the linker between the C- and N-terminal domains. PvGSTU3-3, in general, exhibits restricted ability to bind xenobiotics in a nonsubstrate manner, suggesting that the biological role of $P v$ GSTU3-3, is restricted mainly to the catalytic function. Our findings highlight the functional
\end{abstract}

E. Chronopoulou $\cdot$ N. E. Labrou $(\bowtie)$

Laboratory of Enzyme Technology, Department of Biotechnology, School of Food, Biotechnology and Development, Agricultural University of Athens, 75 Iera Odos Street, 11855 Athens, Greece e-mail: lambrou@aua.gr

P. Madesis $\cdot$ A. Tsaftaris

Institute of Applied Biosciences, CERTH, 6th km Charilaou-Thermis Road, P.O. Box 361, Thermi 57001 Thessaloniki, Greece

A. Tsaftaris

Department of Genetics and Plant Breeding, School of Agriculture, Aristotle University of Thessaloniki, P.O. Box 261, Thessaloniki 54124, Greece 
and catalytic diversity of plant GSTs and demonstrate their pivotal role for addressing biotic stresses in Phaseolus vulgaris.

Keywords Biotic stress $\cdot$ Glutathione transferase $\cdot$ Herbicide detoxification $\cdot$ Homology modeling

\section{Abbreviations}

$\begin{array}{ll}\text { AtGSTs } & \text { Glutathione transferases from Arabidopsis thaliana } \\ \text { BCNB } & \text { 1-Bromo-2,4-dinitrobenzene } \\ \text { CDNB } & \text { 1-Chloro-2,4-dinitrobenzene } \\ \text { CuOOH } & \text { Cumene hydroperoxide } \\ \text { DHAR } & \text { Dehydroascorbate } \\ \text { FDNB } & \text { 1-Fluoro-2,4-dinitrobenzene } \\ \text { Fluorodifen } & \text { 4-Nitrophenyl 2-nitro-4-trifluoromethylphenyl ether } \\ \text { Fluazifop-p-butyl } & \text { Butyl 2- 4-[[5-(trifluoromethyl)-2-pyridinyl]oxy]phenoxy]propanoate } \\ \text { G-site } & \text { Glutathione-binding site } \\ \text { GSH } & \text { Glutathione } \\ \text { GST } & \text { Glutathione transferase } \\ \text { HED } & \text { 2-Hydroxyethyl disulfide } \\ \text { H-site } & \text { Hydrophobic binding site } \\ \text { IDNB } & \text { 1-Iodo-2,4-dinitrobenzene } \\ \text { Nb-GSH } & \text { S-(p-nitrobenzyl)-glutathione } \\ \text { pNPA } & \text { p-Nitrophenyl acetate } \\ \text { PvGST } & \text { Glutathione transferase from Phaseolus vulgaris }\end{array}$

\section{Introduction}

Glutathione transferases (GSTs, EC 2.5.1.18) are multifunctional enzymes that are involved in phase II cellular detoxification mechanism by catalyzing the nucleophilic attack of reduced glutathione (GSH) on the electrophilic center of xenobiotics and toxic metabolites [1,2]. These GSH adducts are more water soluble and can be excreted more easily [3, 4].

Cytosolic GSTs from mammalians, insects, plants, and bacteria are subdivided into classes, based on a variety of criteria such as amino acid, nucleotide sequence, and gene structure as well as tertiary and quaternary structure properties $[3,4]$. Plant GSTs can be subdivided into seven classes: phi $(\mathrm{F})$, tau $(\mathrm{U})$, theta $(\mathrm{T})$, zeta $(\mathrm{Z})$, lambda $(\lambda)$, dehydroascorbate reductase (DHAR), and tetrachlorohydroquinone dehalogenase (TCHQD) [4-6]. Most organisms express different isoenzymes that exhibit different substrate specificities [7, 8]. Organic halides, epoxides, arene oxides, $\alpha$ - and $\beta$-unsaturated carbonyls, organic nitrate esters, and organic thiocyanates are some of the electrophilic molecules that are metabolized by GSTs $[9,10]$. Cytoplasmic GSTs are active as dimers (homodimer or heterodimer), where each subunit (22$29 \mathrm{kDa}$ ) contains GSH-binding site (G-site) in the N-terminal domain and an $\mathrm{H}$-site in the Cterminal domain [1].

GSTs play a crucial role in the protection of cells from a wide range of biotic and abiotic stresses, including pathogen attack, xenobiotic and heavy metal toxins, oxidative stress, and UV radiation $[11,12]$. Their role in stress tolerance in plants is less characterized than their detoxification function [13]; however, GSTs are thought to evolve as part of the cell protection system against oxygen 
toxicity [14]. The antioxidant catalytic function of GSTs [15] is displayed through peroxidase (GPxs) [16], thioltransferase, and dehydroascorbate reductase activity [13, 17]. Plant GSTs exhibit GSH-dependent peroxidase activity (GPx, EC 1.11.1.9) [16, 18] and act protectively against cytotoxicity by reducing organic hydroperoxides to monohydroxyalcohols which are less toxic $[19,20]$. This reaction is important as it prevents the formation of cytotoxic aldehyde derivatives from organic hydroperoxide degradation [20].

The purpose of the present study was to evaluate the function and catalytic diversity of an isoenzyme from Phaseolus vulgaris, which proteomics and transcriptomic studies revealed that, it is expressed under biotic stress treatment of Phaseolus vulgaris plants. Phaseolus vulgaris is the most important grain legume in the world, and it represents a rich source of protein, vitamins, minerals, and fibers for dietary supply. However, available functional genomics and catalomics resources for Phaseolus vulgaris are limited. Such knowledge is a crucial prerequisite for efficient conservation and use of the existing plant varieties for the development of new and improved varieties.

\section{Materials and Methods}

\section{Materials}

Reduced GSH, 1-chloro-2,4-dinitrobenzene (CDNB), $S$-( $p$-nitrobenzyl)-glutathione (NbGSH), and all other enzyme substrates were obtained from Sigma-Aldrich, USA. The $\mathrm{pCR}^{\circledR} \mathrm{T} 7 / \mathrm{CT}-\mathrm{TOPO}{ }^{\circledR}$ kit, TOPO TA Cloning ${ }^{\circledR}$ Kit (with pCR ${ }^{\circledR} 2.1-\mathrm{TOPO}^{\circledR}$ vector), One Shot ${ }^{\circledR}$ Mach1 ${ }^{\mathrm{TM}}$, and SuperScript ${ }^{\mathrm{TM}}$ II Reverse Transcriptase (RT) were purchased from Invitrogen (USA). Phusion Taq DNA polymerase was purchased from FINZYMES (Finland). The plasmid isolation kit and PCR product purification kit were purchased from Macherey-Nagel (Germany), RNeasy Plant Mini Kit was obtained from QIAGEN (UK), and restriction enzymes were purchased from New England Biolabs (UK). P. vulgaris var. plake (florinas) was obtained from the National Agricultural Research Foundation (NAGREF). The pesticides were purchased from Riedel de Haen (Germany).

\section{Plant Growth}

Phaseolus vulgaris var. plake (florinas) seeds were pre-germinated on plates, on Whatman $2 \mathrm{MM}$ filter paper (soaked in distilled water). The plates were kept for $72 \mathrm{~h}$ at $30^{\circ} \mathrm{C}$. After germination, they were transferred into plastic pots in soil. The plants were grown in a controlled environment $\left(12 \mathrm{~h}\right.$ day/12 h night cycle, at $25{ }^{\circ} \mathrm{C}$ day/21 ${ }^{\circ} \mathrm{C}$ night regime and $65 \%$ humidity) and watered with deionized water every four days. Plants grew three to four weeks after germination having three to four pairs of leaves.

\section{Molecular Cloning}

Total RNA from Phaseolus vulgaris roots was isolated using the RNeasy Plant Mini Kit (QIAGEN, UK) and checked through electrophoresis for its integrity. First strand cDNA was synthesized in a total volume of $20 \mu \mathrm{l}$ by using 1-2 $\mu \mathrm{g}$ of total RNA using Superscript II reverse transcriptase (Invitrogen) and $500 \mu \mathrm{g}$ RACE-RT primer 5-GGGCAACTTCT CACTCGGGTTTTTTTTTTTTTTTT-3, $2 \mathrm{mM}$ dNTPs $1 \times$ superscript buffer, $100 \mu \mathrm{M}$ DTT, 1 unit RNAseOUT ${ }^{\mathrm{TM}}$, and 1 unit Superscript II enzyme (added on ice after the first step at $65{ }^{\circ} \mathrm{C}$ ) in a thermocycler using the following conditions $65^{\circ} \mathrm{C}$ for $5 \mathrm{~min}, 42{ }^{\circ} \mathrm{C}$ for $1 \mathrm{~h}$, and then $70{ }^{\circ} \mathrm{C}$ for $15 \mathrm{~min}$. 
Amplification of the GST gene by PCR was performed with phusion Taq DNA polymerase a specific and nested primer for each GST gene and the RACE-AMP 5GGGCAACTTCTCACTCGGG at the $3^{\prime}$ end. A second PCR was performed using the nested specific primer and again the RACE-AMP at the $3^{\prime}$ end. We used the following conditions for all sets of primers in a total volume of $20 \mu \mathrm{l}, 2 \mu \mathrm{l}$ cDNA, $1 \times$ buffer, $5 \mathrm{mM}$ dNTPs $2 \mu \mathrm{M}$ forward and reverse primer each 1 unit of phusion enzyme, and $12.4 \mu \mathrm{l} \mathrm{H}_{2} \mathrm{O}$. The program used in the thermocycler was the same for all sets of primers, with the only exception being the annealing temperature for each set of primers of $98{ }^{\circ} \mathrm{C}$ for $30 \mathrm{~s}, 98{ }^{\circ} \mathrm{C}$ for $10 \mathrm{~s}, T_{\mathrm{m}}$ annealing of $20 \mathrm{~s}$, and $72{ }^{\circ} \mathrm{C}$ for $30 \mathrm{~s}$; the program was repeated for 35 cycles, followed by a step of $72{ }^{\circ} \mathrm{C}$ for $5 \mathrm{~min}$. The primers used were:

\section{GST52F1 5'-GGGCAAACACCCTACTTTCAATTTTGAGCATTAG-3' GST52F2 5'-GGGAGCATTAGCAATGGCTTCAGAAGAGAG.}

The reverse primer was as before the RACE AMP, and the $T_{\mathrm{m}}$ annealing for all PCR reactions was $48{ }^{\circ} \mathrm{C}$. The PCR products were run on $1 \%$ agarose gel, and the genes were cut out and cleaned using the NucleoSpin ${ }^{\circledR}$ Extract II according to the manufacturer's instructions. The clean PCR products were A-tailed using Taq polymerase and then ligated to TOPO TA Cloning ${ }^{\circledR}$ Kit (with pCR ${ }^{\circledR} 2.1-\mathrm{TOPO}{ }^{\circledR}$ vector) cloning kit and sequenced. PCR was used to amplify the fulllength ORFs from $\mathrm{pCR}{ }^{\circledR} 2.1-\mathrm{TOPO}{ }^{\circledR}$ vector using the oligo primers synthesized to the $5^{\prime}$ region of the genes from the ATG start codon and to the $3^{\prime}$ end of the gene. The primer sequences were:

\section{$P v$ GST5F 5'-ATGGCTTCAGAAGAGAGCTCAG-3' $P v$ GST5R 5'-CTATTTCTTTGCAGAAGCTTTG-3'.}

The PCRs were carried out in a total volume of $50 \mu$ that contained the following: 8 pmole of each primer, $1 \mu \mathrm{g}$ template genomic DNA, $50 \mathrm{mM}$ dNTPs, $5 \mu \mathrm{l} 10 \times$ Pfu buffer, and 1 unit of Pfu DNA polymerase. The PCR procedure comprised 30 cycles of $2 \mathrm{~min}$ at $95{ }^{\circ} \mathrm{C}, 2 \mathrm{~min}$ at $55^{\circ} \mathrm{C}$, and $2 \mathrm{~min}$ at $72{ }^{\circ} \mathrm{C}$. A final extension time at $72{ }^{\circ} \mathrm{C}$ for $10 \mathrm{~min}$ was performed after the 30th cycle. The resulting PCR amplicons were TOPO ligated into a T7 expression vector (pEXP5-CT/TOPO $\left.{ }^{\mathbb{B}} \mathrm{TA}\right)$. The resulting expression constructs $\mathrm{pT} 7 \mathrm{Pv} \mathrm{GST}$ sere sequenced and were used to transform competent $E$. coli BL21 (DE3).

\section{Expression and Purification of Recombinant $P v$ GSTU3-3}

E. coli BL21 (DE3) cells harboring recombinant plasmid were grown at $37{ }^{\circ} \mathrm{C}$ in $11 \mathrm{LB}$ medium containing ampicillin $(100 \mu \mathrm{g} / \mathrm{ml})$. The synthesis of GST was induced by the addition of $1 \mathrm{mM}$ isopropyl 1-thio- $\beta$-galactopyranoside (IPTG) when the absorbance at $600 \mathrm{~nm}$ was 0.6 . Four hours after induction, cells were harvested by centrifugation at $8,000 \mathrm{rpm}$ for $20 \mathrm{~min}$, resuspended in potassium phosphate buffer $(0.1 \mathrm{M}, \mathrm{pH} 6.5,9 \mathrm{ml})$, sonicated, and centrifuged at 13,000 rpm for $5 \mathrm{~min}$. The supernatant of $P v$ GSTU3-3 was loaded to a column of glutathione coupled to epoxy-activated Sepharose (1,4-butanediol diglycidyl ether-GSH-Sepharose-CL6B, $1 \mathrm{ml}$ ), which was previously equilibrated with potassium phosphate buffer $(20 \mathrm{mM}, \mathrm{pH} 7)$. Nonadsorbed protein was washed off with $10 \mathrm{ml}$ equilibration buffer. Bound GST was eluted with equilibration buffer containing $10 \mathrm{mM}$ glutathione.

Assay of Enzyme Activity, Protein, and Kinetic Analysis

Enzyme assays for the 1-halogen-2,4-dinitrobenzole derivatives (CDNB, FDNB, BDNB, and IDNB) and fluorodifen conjugation reactions were performed according to published methods $[21,22]$. Other substrates used were ethacrynic acid, p-nitrobenzylchloride (p- 
NBC), bromosulfophthalein and trans-4-phenyl-3-buten-2-one according to the methods of Habig and Jakoby [6], cumene hydroperoxide $(\mathrm{CuOOH})$, tert-butyl hydroperoxide, lauroyl peroxide, benzoyl peroxide [23], 4-chloro-7-nitrobenzofurazan [24], trans-2-nonenal [25], sulphanilamide [22], phenethyl isothiocyanate, and allyl isothiocyanate [26]. Dehydroascorbate reductase and thioltransferase activity using dehydroascorbate (DHAR) and 2-hydroxyethyl disulfide (HED) as substrates were carried out as described in Allocati et al. [27]. In addition, enzyme assays were performed for the herbicides fluazifop-p-butyl, alachlor, metolachlor, and atrazine [28].

The electrophilic substrates were dissolved in either ethanol or acetonitrile to final concentrations of $2-5 \%(v / v)$ of the organic solvent in the assay solutions. Observed reaction velocities were corrected for spontaneous reaction rates when necessary. All initial velocities were determined in triplicate in buffers equilibrated at constant temperature. One unit of enzyme activity is defined as the amount of enzyme that catalyzes the turnover of $1 \mu \mathrm{mol}$ of substrate per minute. Specific activity is expressed in micromole per minute per milligram of protein. Protein concentration was determined by the Bradford assay using bovine serum albumin (fraction V) as standard.

Steady-state kinetic measurements were performed at $37{ }^{\circ} \mathrm{C}$. Initial velocities were determined in the presence of $2.5 \mathrm{mM} \mathrm{GSH}$ and CDNB which was used in the concentration range of $0.15-1.8 \mathrm{mM}$. Alternatively, CDNB was used at a final concentration of $1 \mathrm{mM}$, while the GSH concentration was varied in the range of $0.0075-0.2 \mathrm{mM}$. Steady-state data were fitted to the Michaelis-Menten equation by nonlinear regression analysis using the Grafit version 3.03 (Erithacus Software Ltd.) computer program.

Inhibition potency of xenobiotics towards $P v$ GSTU3-3 was carried out in the assay system described above in the presence of $100 \mu \mathrm{M}$ pesticide diluted in acetone. During the course of the assay (30-60 s), no measurable pesticide/GSH reaction was detected. The percentage enzyme inhibition (\% I) was calculated using the following equation:

$$
\% \text { Inhibition }=\frac{R_{0}-R_{i}}{R_{0}}
$$

where $R_{\mathrm{o}}$ is the rate of absorbance increase for the uninhibited reaction and $R_{i}$ is the rate of increase for the inhibited reaction. Both $R_{i}$ and $R_{\mathrm{o}}$ correspond to the same substrate concentration.

\section{Bioinformatics Analysis and Molecular Modeling}

GST sequences from phi, tau, zeta, theta, lambda, dehydroascorbate reductase, and tetrachlorohydroquinone dehalogenase classes and sequences homologous to PvGSTs were sought in the NCBI using pBLAST. The resulting sequence set was aligned with ClustalW using BLOSUM62 as scoring matrix. Geneious v5.5 [29] was used for alignment visualization and manipulation. Homology models were constructed using the program MODELLER [30] as implemented in UCSF Chimira (http://www.cgl.ucsf.edu/chimera) [31], and five models were produced in each case. An iterative protocol involving model constructions and rigorous protein structure quality assessment, using PROSA II [32] and Verify 3D [33], was used. The crystal structures of GSTs that were used as templates for PvGSTU3-3 were 1GWC, 1OYJ, and 2VO4 from Protein Data Bank (http:/www.rcsb.org/pdb/home/ home.do). For inspection of models and crystal structures, the program PyMOL (http:// www.pymol.org/ [34]) and UCSF Chimera were used. Coulombic surface analysis was 
carried out using UCSF Chimera. Phylogenetic analysis was carried out using Geneious v5.5 program [29].

\section{Results and Discussion}

Cloning and Sequence Analysis of the PvGSTs

Liquid chromatography tandem mass spectrometry analysis of the proteins from the crop plant Phaseolus vulgaris infected by the rust fungus $U$. appendiculatus reveals the presence of distinct GST proteins that are differentially expressed in infected plants [35]. One of them with N-terminal sequence MASEESSEVRVLGKWASP is particularly overexpressed, suggesting that may be part of the plant defense mechanism. In silico searches of $P$. vulgaris infected by the bean rust pathogen $U$. appendiculatus expressed sequence tag (EST) library revealed the presence of a transcript (GenBank accession number FE701112) coding for this GST isoenzyme [36]. RACE-RT PCR was used to obtain its 663-bp full open reading frame. The cDNA encodes a polypeptide of 221 amino acid residues and molecular mass of 25,071.91 Da with theoretical pI of 5.70 (Fig. 1). In silico analysis, using iPSORT, TargetP, and SignalP algorithms, revealed the absence of putative Nterminal transit peptide, suggesting that is a cytosolic enzyme. Figure 1 depicts the phylogenetic relationship of the P. vulgaris GST with other GSTs from all known plant classes. This GST is clustered together with plant tau class GSTs. According to the nomenclature of Edwards et al. [17], as recently adopted for $P$. vulgaris GSTs [1], this isoenzyme may be termed as PvGSTU3-3.

Expression, Purification, and Kinetic Analysis Using the Model Substrate 1-Chloro-2,4-dinitrobenzene

The coding sequences of $P v$ GSTU3-3 were amplified by PCR and ligated into a T7 expression vector, and the resulting expression construct (pT7PvGSTU3-3) was used to transform competent $E$. coli BL21(DE3) cells. Recombinant $P v$ GSTU3-3 was purified (Fig. 2) by affinity chromatography on immobilized GSH column. Steady-state kinetic analysis of recombinant PvGSTU3-3 using the model substrate system CDNB/GSH was carried out, and the $k_{\text {cat }}$, and $K_{\mathrm{m}}$ parameters were determined (Fig. 3; Table 1). The results showed that the enzyme obeys Michaelis-Menten kinetics. The $K_{\mathrm{m}}$ value of PvGSTU3-3 for CDNB falls within the range expected for plant GSTs (Table 1). However, the $K_{\mathrm{m}}{ }^{\mathrm{GSH}}$ for PvGSTU3-3 (23 $\left.\pm 2.2 \mu \mathrm{M}\right)$ differs significantly compared to other plant GSTs and, in particular, is about five to ten times lower [37] as, for example, the isoenzyme GmGSTU4-4 [22] or the isoenzyme ZmGSTF1-1 [23]. The low $K_{\mathrm{m}}{ }^{\mathrm{GSH}}$ suggests that $P v \mathrm{GSTU} 3-3$ is able to work efficiently under conditions where the concentration of reduced GSH is low (e.g., oxidative stress).

\section{Substrate Specificity of the Recombinant $P v$ GSTU3-3}

The substrate specificity of $P v$ GSTU3-3 was investigated in order to identify catalytic activities that may be related to its biological function. The assays included tests of thioether and thioester formation, i.e., nucleophilic attack at carbon as well as at electrophilic sulfur with an organic thiocyanate as substrate, tests for peroxidase, dehydroascorbate reductase, and thioltransferase activity. As shown in Table 2, $P v$ GSTU3-3 catalyzes a broad range of reactions, exhibiting quite varied substrate specificity. $P v$ GSTU3-3 exhibited activity towards 17 out of 23 different substrates that were tested. In general, $P v$ GSTU3-3 is active 


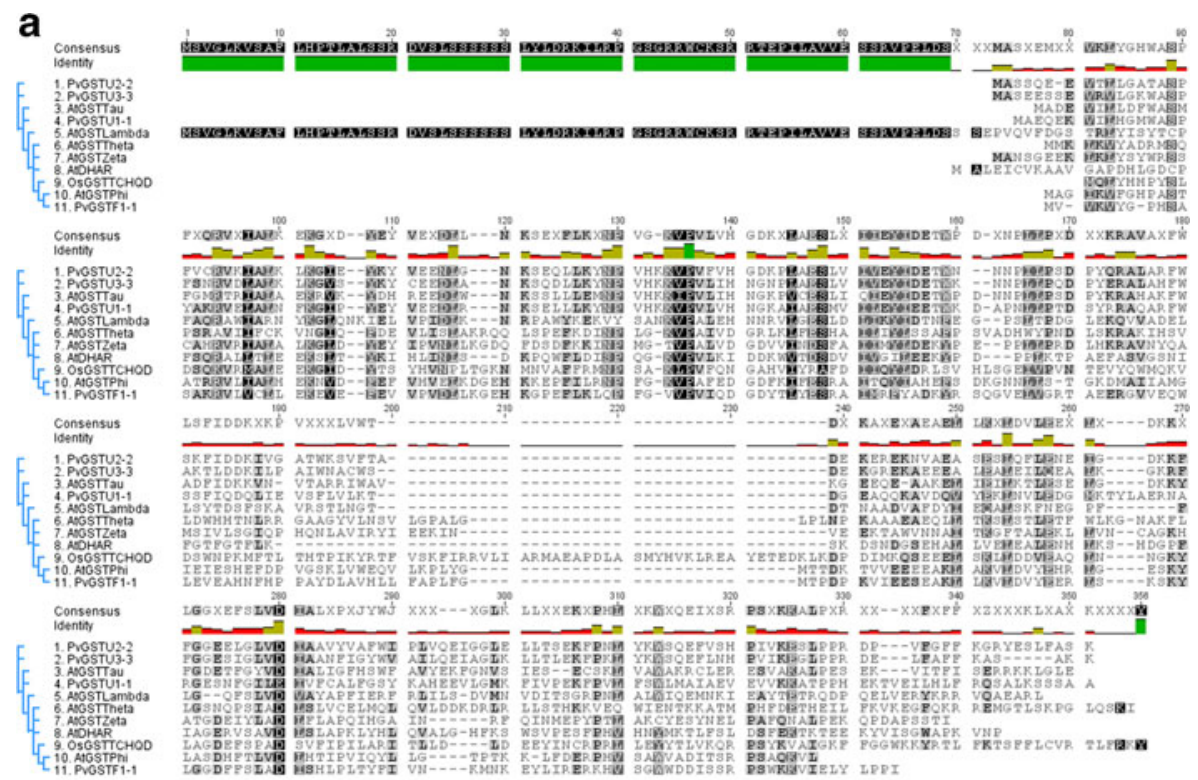

b

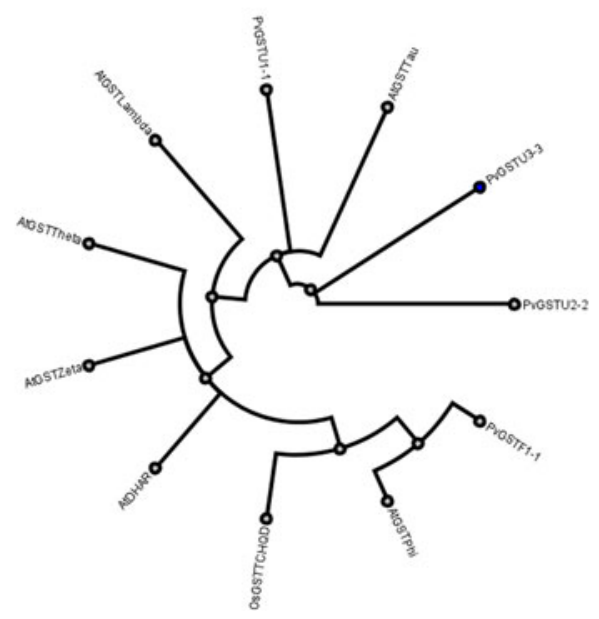

Fig. 1 a Sequence alignments (ClustalW) of $P v$ GSTU3-3 and representative members from all known GST classes: phi, tau, theta, zeta, lambda, dehydroascorbate reductase (DHAR), and tetrachlorohydroquinone dehalogenase (TCHQD). The figure was created using Geneious v5.5 [29]. Conserved areas are shown shaded, with gray gradient: $100 \%$ identity, 80-100\% identity, 60-80\% identity, and $<60 \%$ identity. b Phylogenetic analysis of $P v \mathrm{GSTU} 3-3$. Phylogenetic tree was constructed by neighbor-joining method using the Geneious v5.5 program [29] and representative members from all known plant GST classes and $P v$ GSTU3-3. The tree was formed after alignment of the protein sequences using ClustalW. The accession numbers of the GST sequences that were used were AtGSTPhi (Arabidopsis thaliana phi class GST, NP_171792), AtGSTTheta (Arabidopsis thaliana theta class GST, NP_198937), AtDHAR (Arabidopsis thaliana dehydroascorbate reductase, Q9FWR4), AtGSTZeta (Arabidopsis thaliana zeta class GST, Q9ZVQ3), AtGSTTau (Arabidopsis thaliana tau class GST, AAS76278), PvGSTU1-1 (Phaseolus vulgaris tau class GST, AEX38000.1), PvGSTU2-2 (Phaseolus vulgaris tau class GST, AEX38001.1), AtGSTLambda (Arabidopsis thaliana lambda class GST, NP_191064), and OsGSTTCHQD (Oriza sativa tetrachlorohydroquinone dehalogenase, CAZ68077) 
Fig. 2 SDS-PAGE analysis of purified $P v$ GSTU3-3. $M$ protein markers, lane 1 crude extract, lanes 2-4 eluted fractions from the affinity column

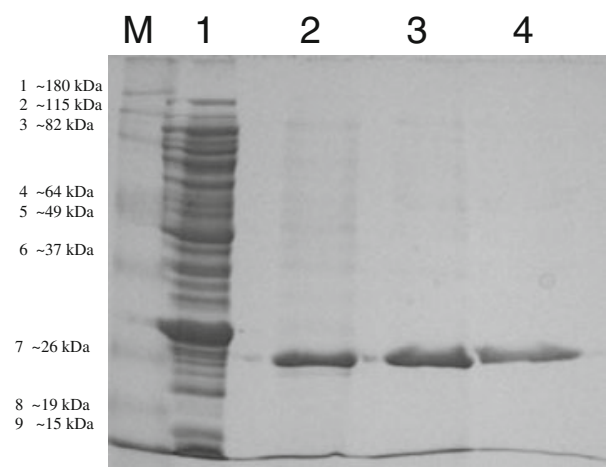

towards the synthetic halogenated aromatic compounds such as 1-bromo-2,4-dinitrobenzene (BDNB), 1-fluoro-2,4-dinitrobenzene (FDNB), 1-iodo-2,4-dinitrobenzene (IDNB). PvGSTU3-3 was also assayed towards herbicide/GSH conjugation reactions. As shown in Table 2, the enzyme is able to catalyze the GSH conjugation to the electrophilic herbicides that belong to phenoxy (fluazifop-p-butyl), triazines (atrazine), and acetanilides (alachlor, metolachlor). It is noteworthy that the enzyme did not show activity toward the nitrophenyl ether herbicide fluorodifen, a common feature of tau class GSTs as, for example, the isoenzyme GmGSTU4-4 [22].

GSTs catalyze the nucleophilic attack of GSH on organic hydroperoxides to the less-toxic monohydroxy alcohols [17]. It is believed that GSTs with high glutathione peroxidase activity (GPx) appear to contribute to oxidative stress resistance by preventing the accumulation of cytotoxic hydroperoxides and cytotoxic aldehyde derivatives which are formed either directly or indirectly as a result of oxidative stress [20]. In addition to the direct protective effect of the GPx activity, the GPx-mediated increase in GSSG concentration in the cells may function as a signal to activate further protective stress response mechanisms [38-40]. PvGSTU3-3 was assayed for GSH-dependent peroxidase activity employing four different hydroperoxides (cumene hydroperoxide, tert-butyl hydroperoxide, lauroyl-peroxide, and benzoyl-peroxide) as substrates (Table 2). Among all peroxides assayed, benzoyl-peroxide

a

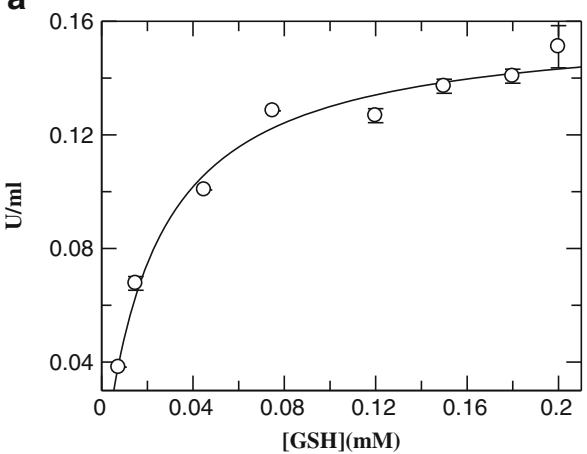

b

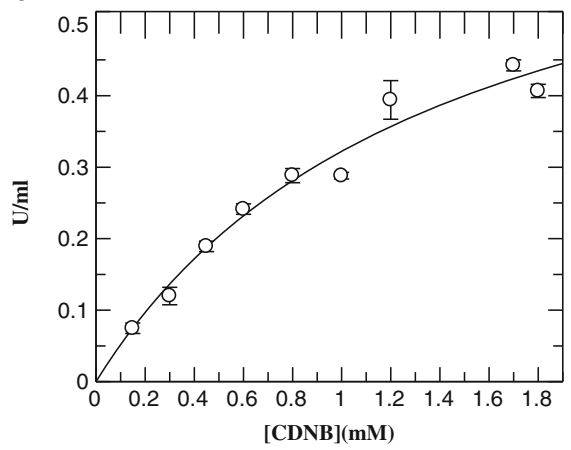

Fig. 3 Kinetic analysis of $P v$ GSTU3-3 using the GSH as a variable substrate (a) and CDNB at a fixed concentration. Kinetic analysis of $P v$ GSTU3-3 using the CDNB as variable substrate (b) and GSH at a fixed concentration. Experiments were performed in triplicate, and lines were those calculated by least-squares regression analysis 
Table 1 Steady-state kinetic analysis of PvGSTU3-3 for the CDNB/GSH substrate system

\begin{tabular}{lllllll}
\hline $\begin{array}{l}\text { Electrophilic } \\
\text { substrate/ } \\
\text { enzyme }\end{array}$ & $\begin{array}{l}K_{\mathrm{m}}(\mu \mathrm{M}) \\
(\mathrm{GSH})\end{array}$ & $\begin{array}{l}K_{\mathrm{cat}}\left(\mathrm{min}^{-1}\right) \\
(\mathrm{GSH})\end{array}$ & $\begin{array}{l}K_{\mathrm{m}}(\mu \mathrm{M}) \\
(\mathrm{CDNB})\end{array}$ & $\begin{array}{l}k_{\mathrm{cat}}\left(\mathrm{min}^{-1}\right) \\
(\mathrm{CDNB})\end{array}$ & $\begin{array}{l}k_{\mathrm{cat}} / K_{\mathrm{m}} \\
\left(\mu \mathrm{M}^{-1} \min ^{-1}\right) \\
(\mathrm{GSH})\end{array}$ & $\begin{array}{l}k_{\mathrm{cat}} / K_{\mathrm{m}} \\
\left(\mu \mathrm{M}^{-1} \mathrm{~min}^{-1}\right) \\
(\mathrm{CDNB})\end{array}$ \\
\hline \begin{tabular}{l}
$P$ GSTU3-3 \\
\hline
\end{tabular} & $23 \pm 2.2$ & $72.8 \pm 1.6$ & $1,399 \pm 246$ & $351.2 \pm 34.1$ & $3.2 \pm 0.4$ & $0.26 \pm 0.07$ \\
\hline
\end{tabular}

was the best substrate for $P v G S T U 3-3$. The high catalytic efficiency of $P v G S T U 3-3$ towards organic hydroperoxides may provide a link to the in vivo functional role of the enzyme towards oxidative stress tolerance. It is well acceptable that GSTs play an important role in counteracting oxidative stress conditions. For example, co-silencing of a group of four phi GSTs in Arabidopsis resulted in altered metabolic sensitivity to oxidative stress [2].

In addition to GSH-peroxidase activity, the antioxidant function of GSTs is also displayed by their dehydroascorbate reductase and thioltransferase activity [7]. PvGSTU3-3 catalyzes the reduction of dehydroascorbate to ascorbic acid using GSH and exhibits thioltransferase activity using 2-hydroxyethyl disulfide as a substrate. These activities indicate that this

Table 2 Substrate specificity for purified recombinant $P v$ GSTU3-3. Enzyme assays were carried out under standard conditions as described in the "Methods" section. Results represent the means of triplicate determinations, with variation less than $5 \%$ in all cases

\begin{tabular}{|c|c|}
\hline Substrate & Specific activity $(\mathrm{U} / \mathrm{mg})$ \\
\hline 1-Chloro-2,4-dinitrobenzene & 3.5 \\
\hline 1-Bromo-2,4-dinitrobenzene & 2.8 \\
\hline 1-Fluoro-2,4-dinitrobenzene & 0.5 \\
\hline 1-Iodo-2,4-dinitrobenzene & 1.6 \\
\hline p-Nitrobenzyl chloride & ND \\
\hline 4-Chloro-7-nitrobenzofurazan & 1.9 \\
\hline Cumene hydroperoxide & 0.6 \\
\hline tert-Butyl hydroperoxide & 0.4 \\
\hline Lauroyl peroxide & 0.2 \\
\hline Benzoyl peroxide & 1.4 \\
\hline trans-2-Nonenal & $\mathrm{ND}$ \\
\hline trans-4-Phenyl-3-buten-2-one & $\mathrm{ND}$ \\
\hline 2,3-Dichloro-4-[2-methylene-butyryl]phenoxy) acetic acid (ethacrynic acid) & $\mathrm{ND}$ \\
\hline Fluazifop-p-butyl & 0.3 \\
\hline Alachlor & 0.1 \\
\hline Metolachlor & 0.03 \\
\hline Atrazine & 0.01 \\
\hline Fluorodifen & $\mathrm{ND}$ \\
\hline Sulphanilamide & $\mathrm{ND}$ \\
\hline Phenethyl isothiocyanate & 0.1 \\
\hline 2-Hydroxyethyl disulfide (2,2-dithiodiethanol) & 0.4 \\
\hline Dehydroascorbate & 1.5 \\
\hline Bromosulfophthalein & 3.5 \\
\hline
\end{tabular}

$N D$ nondetectable activity 
isoenzyme may play a regulatory role in the antioxidant mechanism. It is well acceptable that under oxidative stress in the absence of GSH, some protein thiols are S-thiolated making protein-thiol disulfides. Thiolation/dethiolation reactions play regulatory and/or protective role for proteins [41].

Isothiocyanates are plant substances that are released after cleavage of glucosinolates by a plant enzyme thioglucosidase (myrosinase), as a response to injury or other forms of stress. GSTs were found to catalyze the conjugation of naturally occurring isothiocyanates to GSH [42]. In particular, GSTs are able to catalyze the addition of the thiol group of GSH to the electrophilic central carbon of the isothiocyanate group to form dithiocarbamates [R-NH$\mathrm{C}(=\mathrm{S})-\mathrm{SG}$. $P v \mathrm{GSTU} 3-3$ can catalyze the reaction of GSH with phenethyl isothiocyanate. Isothiocyanates are part of the plant defense mechanism with antimicrobial effects and can also act as repellents or attractants for insects [43].

\section{Molecular Modeling}

In attempts to understand at molecular-level the structural and catalytic properties of PvGSTU3-3, homology modeling was carried out based on the available X-ray structures of plant tau class GSTs. As illustrated in Fig. 4, PvGSTU3-3 adopts the canonical GST fold that consists of two distinct domains: a smaller thioredoxin-like $\mathrm{N}$-terminal domain and a larger helical C-terminal domain [7, 22, 44]. The $\mathrm{N}$-terminal domain is an $\alpha / \beta$ structure with the folding topology $\beta \alpha \beta \alpha \beta \beta \alpha$. B-sheets follow the order $\beta 1, \beta 2, \beta 3$, and $\beta 4$, with $\beta 3$ being anti-parallel to the others. At the end of the helix, $\mathrm{H} 3$ begins a short linker that joins the $\mathrm{N}$ - and $\mathrm{C}$-terminal domains. The core of the $\mathrm{C}$-terminal domain is a bundle of four helices (H4H5H6H7). The structure of $P v$ GSTU3-3 reveals that the central four-stranded $\beta$ sheet and the up and down arrangements of helices $\mathrm{H} 4$ and $\mathrm{H} 5$ are similar to other tau class GSTs [7, 22, 44]. Its structure exhibits differences to other GSTs in the linker segment, the $\mathrm{C}$-terminal region and the region of the helix joining strands $\beta 2$ and $\beta 3$.

In each subunit exists one active site consisting of the two distinct subsites: a GSHbinding site (G-site) and a binding pocket for hydrophobic substrates (H-site). Amino acid residues that participate in G-site formation are Ser17, Phe19, Lys44, Val58, Glu70, and Ser71. Surface analysis (Fig. 4b) showed that the G-site of PvGSTU3-3 displays a positive electrostatic potential. The positive electrostatic potential may contribute to an efficient binding to GSH and may explain the substantial high affinity of $P v$ GSTU3-3 for GSH (low $K_{\mathrm{m}}{ }^{\mathrm{GSH}}$, Table 2). It is well established that the plant tau class enzymes possess Ser as a catalytic residue $[22,23,44]$. This Ser residue is located at the N-terminal domain of the protein and is involved in catalysis by activating the - $\mathrm{SH}$ group of bound GSH. Analysis of PvGSTU-3-3 modeled structure shows that Ser17 is a conserved residue (Figs. 1 and 4) that could be the catalytically important amino acid. Different GST classes employ different catalytic residues. For example, in alpha, mu, pi, and sigma, the active site residue is a Tyr. In the delta, epsilon, theta, phi, tau, and zeta GSTs, the active site residue is a Ser, and in omega and beta class GSTs, it is a Cys [4, 7, 13, 17].

The H-site of PvGSTU3-3 is situated adjacent to the G-site and defines the substrate specificity of the enzyme. It is a large, open cleft and exhibits a low degree of sequence identity (Figs. 1 and 4), hence a unique structure, compared to other tau class GSTs [22]. The H-site of PvGSTU3-3 is hydrophobic in nature, composed of a large number of aromatic residues. The structural heterogeneity within the $\mathrm{H}$-site is responsible for the different specificity, compared to the other $P v$ GSTs [1]. The main amino acid residues that participate in H-site formation are Phe19, Trp114, Trp118, Tyr165, Trp166, Phe213, and Phe214. However, a few positive charged residues (e.g., Lys57 and Lys220) are located at the entrance of the H-site and make 

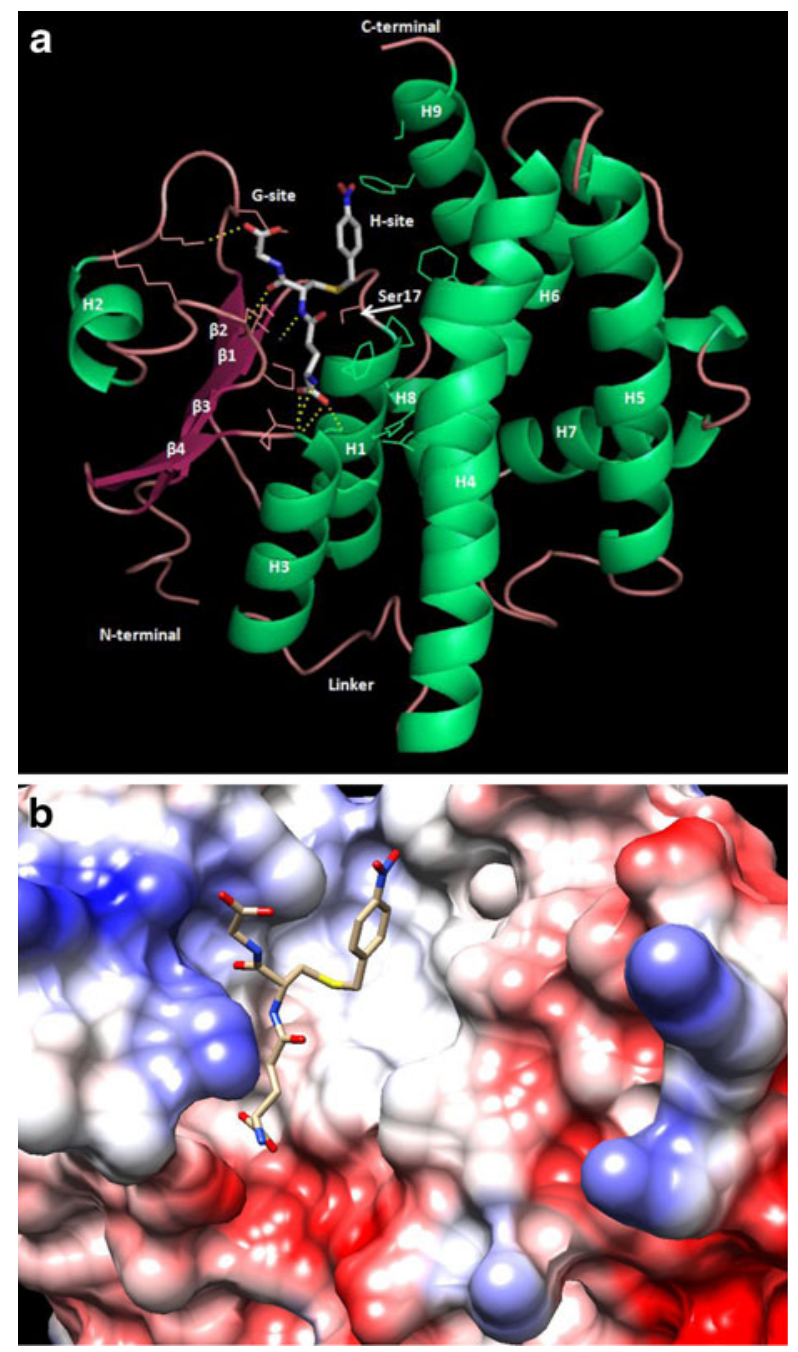

Fig. 4 a Ribbon diagrams of the PvGSTU3-3 protein model. B-strands are in warm pink and helices (H) are in lime green. The locations of active site Ser residue, the $\mathrm{G}$ - and $\mathrm{H}$-sites as well as the $\mathrm{C}$ - and $\mathrm{N}$-terminal, and the linker segment are labeled. The figure was created using PyMOL [34]. b Coulombic surface analysis of PvGSTU3-3. The analysis was carried out using UCSF Chimera (http://www.cgl.ucsf.edu/chimera)

the approach to the H-site basic. These basic residues form a positively charged region at the $\mathrm{H}$-site, which presumably enable the enzyme to bind negatively charged substrates.

Probing the Ligandin-Binding Site of $P v$ GSTU3-3 by Xenobiotics

GSTs exhibit a ligand-binding ("ligandin") function, facilitating the binding of numerous hydrophobic and amphiphatic compounds in a nonsubstrate manner into a distinct site that is termed Lsite. Binding of such ligands results in the inhibition of GST catalytic activity [22, 45-47]. To probe the ligandin function of $P v$ GSTU-3-3, a wide range of xenobiotics (insecticides, fungicides, and herbicides) were employed. The inhibition potency of the xenobiotics is shown in Fig. 5. All 


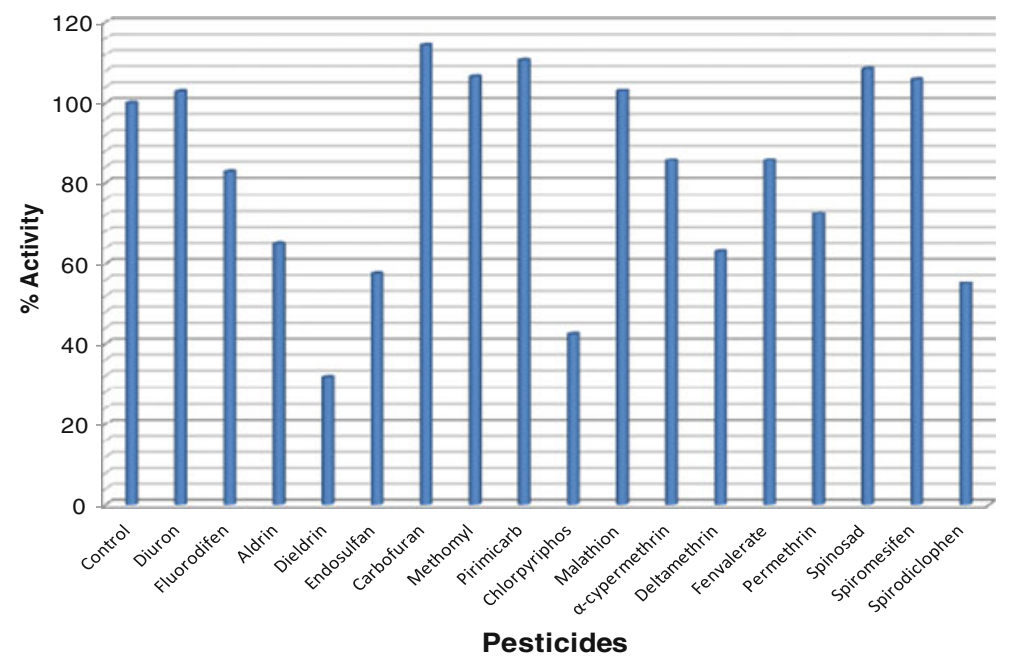

Fig. 5 Probing the $P v$ GSTU3-3 L-site. Screening of the inhibition potency of different pesticides towards $P v$ GSTU3-3. GST activity was assayed using the CDNB/GSH assay system

xenobiotics showed time-independent inhibition, indicating that the inhibitors bind reversibly to the enzymes. From the results presented in Fig. 5, it is evident that bulky compounds with two aromatic rings (e.g., phenylurea-based insecticides such as fenvalerate, fluorodifen, permethrin, and $\alpha$-cypermethrin) displayed moderate inhibition potency, showing approximately $10-40 \%$ inhibition. Aliphatic insecticides such as malathion and pesticides with one aromatic ring (e.g., diuron) exhibited low or no inhibition potency, with the exception of chlorpyrifos that shows high inhibition potency $(>50 \%)$. The organochlorine insecticides (e.g., aldrin, dieldrin, and endosulphan) showed moderate inhibition, resulting in a decrease of $P v$ GSTU-3-3 activity by $40-60 \%$ (Fig. 5). The results of this study show that $P v$ GSTU-3-3 exhibits restricted ability to bind xenobiotics, in a nonsubstrate manner, compared to other GST isoenzymes [22, 48]. This observation probably suggests that the enzyme does not act as a ligandin protein and presumably its biological role is restricted mainly to the catalytic function. Little information is available about the localization of the L-site in GSTs. Biocomputing analysis using the CASTp software enabled the identification of the main pockets in the PvGSTU3-3 enzyme (Fig. 6). Three putative binding pockets were identified, and they presumably represent the putative L-sites of $P v$ GSTU3-3. The largest pocket (area $698.9 \mathrm{~A}^{2}$ and volume $858.7 \mathrm{~A}^{3}$ ) is formed between $\mathrm{H} 5, \mathrm{H} 6, \mathrm{H} 7$, and $\mathrm{H} 9$ helices. The second (area 544.4 $\mathrm{A}^{2}$ and volume $994.9 \mathrm{~A}^{3}$ ) overlaps the G- and H-sites, and the third, which is significantly smaller compared to the other two, is formed by the H4, H5, and H7 helices (area $233.9 \mathrm{~A}^{2}$ and volume $413.1 \mathrm{~A}^{3}$ ).

The role of L-site in GSTs is unclear. However, it is widely acceptable that the binding of nonsubstrate ligands in the L-site of GSTs may provide protection (e.g., degradation and oxidation) of the molecules in vivo. Another possibility is that GSTs with ligandin function may prevent cellular damage that is caused by endogenous and xenobiotic toxic compounds. The other possibility is that binding to L-site may help to the delivery of selected ligands to specific cellular protein receptors or compartments [49-51]. It is well known that the tau class GSTs exhibit ligandin function. For example, the tau class isoenzymes from Arabidopsis thaliana are able to bind thioester of fatty acids with varied chain length (C[6] to C[18]), oxygen content, and desaturation, with $K_{\mathrm{D}^{\sim}} \mu \mathrm{M}$ [48]. Axarli et al. [22] have reported that the isoenzyme GmGSTU4-4 is able to bind (4-nitrophenyl)methanethiol. 
a

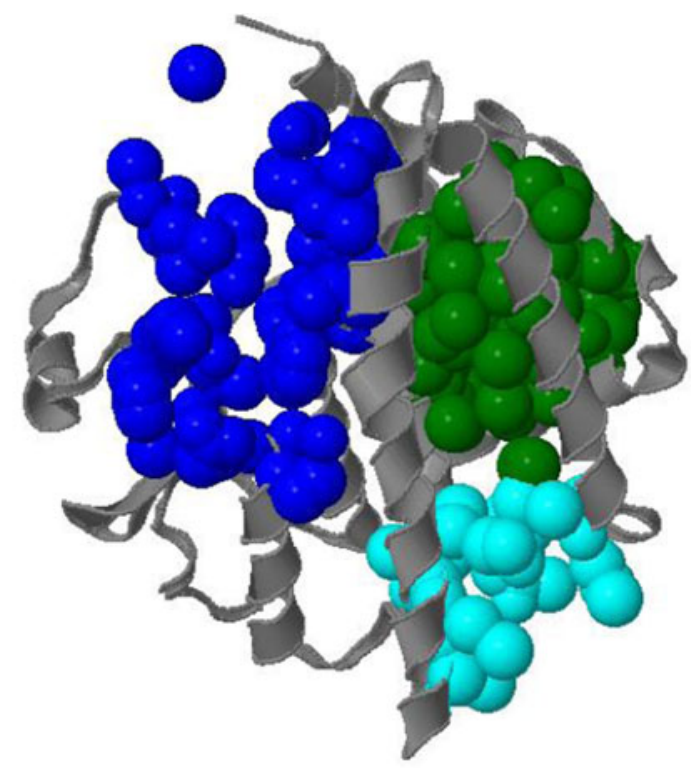

b

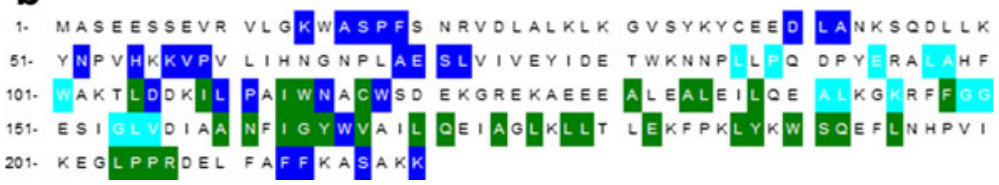

Fig. 6 Biocomputing analysis for the identification of the main large pockets (putative L-sites) in the PvGSTU3-3 enzyme. a Ribbon diagrams of PvGSTU3-3 protein model showing the three main binding pockets colored in green (the largest pocket formed between $\mathrm{H} 5, \mathrm{H} 6, \mathrm{H} 7$, and $\mathrm{H} 9$ helices), blue (overlaps the G- and H-sites), and turquoise (the smaller formed by the H4, H5, and $\mathrm{H} 7$ helices). b Amino acid residues that contribute to the formation of the three main binding pockets of PvGSTU3-3 colored in green, blue, and turquoise

The binding site of this compound is located in a hydrophobic surface pocket, formed by Trp11, Arg20, Tyr30, Tyr32, Leu199, and Pro200.

\section{Conclusions}

In conclusion, in the present work, we describe the characterization of a tau class GST isoenzyme from Phaseolus vulgaris which is induced in protein and RNA level following $U$. appendiculatus infection. The results showed that $P v$ GSTU3-3 catalyzes several different reactions and exhibits wide substrate specificity. Structural analysis showed that PvGSTU3-3 shares the same overall fold and domain organization of other tau class plant cytosolic GSTs, with major differences at the H-site. PvGSTU3-3, in general, exhibits restricted ability to bind xenobiotics in a nonsubstrate manner, suggesting that its biological role is restricted mainly to the catalytic function. Our findings shed light on better understanding the PvGSTU3-3 functional and catalytic diversity and highlight the pivotal role of GSTs used by plants to cope with biotic stress. 
Acknowledgments This research was co-financed by the European Union (European Social Fund-ESF) and Greek national funds through the Operational Program "Education and Lifelong Learning" of the National Strategic Reference Framework (NSRF) - Research Funding Program: Heraclitus II, investing in knowledge society through the European Social Fund.

\section{References}

1. Chronopoulou, E., Madesis, P., Asimakopoulou, B., Platis, D., Tsaftaris, A., \& Labrou, N. E. (2012). Planta, 235, 1253-1269.

2. Sappl, P. G., Carroll, A. J., Clifton, R., Lister, R., Whelan, J., Harvey Millar, A., et al. (2009). Plant Journal, 58, 53-68.

3. Cummins, I., Dixon, D. P., Freitag-Pohl, S., Skipsey, M., \& Edwards, R. (2011). Drug Metabolism Reviews, 43, 266-280.

4. Chronopoulou, E., \& Labrou, N. E. (2009). Recent Patents on Biotechnology, 3, 211-223.

5. Dixon, D. P., Skipsey, M., \& Edwards, R. (2010). Phytochemistry, 71, 338-350.

6. McGonigle, B., Keeler, S. J., Lau, S. M., Koeppe, M. K., \& O'Keefe, D. P. (2000). Plant Physiology, 124, 1105-1120.

7. Chronopoulou, E., Axarli, I., Nianiou-Obeidat, I., Madesis, P., Tsaftaris, A., \& Labrou, N. E. (2011). Current Opinion in Chemical Biology, 5, 64-74.

8. Wiktelius, E., \& Stenberg, G. (2007). Biochemical Journal, 406, 115-123.

9. Hayes, J. D., Flanagan, J. U., \& Jowsey, I. R. (2005). Annual Review of Pharmacology and Toxicology, 45, 51-88.

10. Ranson, H., \& Hemingay, J. (2005). Methods in Enzymology, 401, 226-241.

11. Kampranis, S. C., Damianova, R., Atallah, M., Toby, G., Kondi, G., Tsichlis, P. N., et al. (2000). Journal of Biological Chemistry, 275, 29207-29216.

12. Thom, R., Cummins, I., Dixon, D. P., Edwards, R., Cole, D. J., \& Lapthorn, A. J. (2002). Biochemistry, $41,7008-7020$.

13. Frova, C. (2003). Physiologia Plantarum, 119, 469-479.

14. Mannervik, B. (1985). Methods in Enzymology, 113, 490-495.

15. Dixon, D. P., Davies, B. G., \& Edwards, R. (2002). Journal of Biological Chemistry, 277, 30859-30869.

16. Cummins, I., Cole, D. J., \& Edwards, R. (1999). Plant Journal, 18, 285-292.

17. Edwards, R., Dixon, D. P., \& Walbot, V. (2000). Trends in Plant Science, 5, 193-198.

18. Bartling, D., Radzio, R., Steiner, U., \& Weiler, E. W. (1993). European Journal of Biochemistry, 216, 579-586.

19. Marrs, K. A. (1996). Annual Review of Plant Physiology and Plant Molecular Biology, 47, $127-158$.

20. Dixon, D. P., Lapthorn, A., \& Edwards, R. (2002). Genome Biology, 3, 3004.1-3004.10.

21. Skopelitou, K., Muleta, A. W., Pavli, O., Skaracis, G. N., Flemetakis, E., Papageorgiou, A. C., et al. (2012). Functional \& Integrative Genomics, 12, 157-172.

22. Axarli, I., Dhavala, P., Papageorgiou, A. C., \& Labrou, N. E. (2009). Journal of Molecular Biology, 385, 984-1002.

23. Labrou, N. E., Mello, L. V., \& Clonis, Y. D. (2001). Biochemical Journal, 358, 101-110.

24. Sommer, A., \& Buger, P. (1999). Pesticide Biochemistry and Physiology, 63, 127-138.

25. Esterbauer, H., Benedetti, A., Lang, J., Fulceri, R., Fauler, G., \& Comporti, M. (1986). Biochimica et Biophysica Acta, 876, 154-166.

26. Kolm, R. H., Danielson, U. H., Zhang, Y., Talalay, P., \& Mannervik, B. (1995). Biochemical Journal, 311 , 453-459.

27. Allocati, N., Favaloro, B., Masulli, M., Alexeyev, M. F., \& Di Ilio, C. (2002). Biochemical Journal, 373, 305-311.

28. Shimabukuro, R. H., Frear, D. S., Swanson, H. R., \& Walsh, W. C. (1971). Plant Physiology, 47, $10-14$.

29. Drummond, A. J., Ashton, B., Buxton, S., Cheung, M., Cooper, A., Duran, C., et al. (2011). Geneious v5.5. Available from http://www.geneious.com.

30. Sali, A., \& Blundell, T. L. (1993). Journal of Molecular Biology, 234, 779-815.

31. Pettersen, E. F., Goddard, T. D., Huang, C. C., Couch, G. S., Greenblatt, D. M., Meng, E. C., et al. (2004). UCSF Chimera-a visualization system for exploratory research and analysis. Journal of Computational Chemistry, 25, 1605-1612.

32. Sippl, M. J. (1993). Proteins, 17, 355-362.

33. Luthy, R., Bowie, J. U., \& Eisenberg, D. (1992). Nature, 356, 83-85. 
34. DeLano, W. L. (2002). The PyMOL molecular graphics system DeLano scientific. San Carlos, CA, USA.

35. Lee, J., Feng, J., Campbell, K. B., Scheffler, B. E., Garrett, W. M., Thibivilliers, S., et al. (2009). Molecular and Cellular Proteomics, 8, 19-31.

36. Thibivilliers, S., Joshi, T., Campbell, K. B., Scheffler, B. E., Xu, D., Cooper, B., et al. (2009). BMC Plant Biology, 9, 46-59.

37. Kunieda, T., Fujiwara, T., Amano, T., \& Shioi, Y. (2005). Plant and Cell Physiology, 46, 1540-1548.

38. Filomeni, G., Rotilio, G., \& Ciriolo, M. R. (2003). FASEB Journal, 17, 64-66.

39. Circu, M. L., \& Aw, T. Y. (2008). Free Radical Research, 42, 689-706.

40. Schafer, F. Q., \& Buettner, G. R. (2001). Free Radical Biology and Medicine, 30, 1191-1212.

41. Spadaro, D., Yun, B. W., Spoel, S. H., Chu, C., Wang, Y. Q., \& Loake, G. J. (2010). Physiologia Plantarum, 138, 360-371.

42. Meyer, D. J., Crease, D. J., \& Ketterer, B. (1995). Biochemical Journal, 306, 565-569.

43. Fahey, J. W., Zalcmann, A. T., \& Talalay, P. (2001). Phytochemistry, 56, 5-51.

44. Axarli, I., Dhavala, P., Papageorgiou, A. C., \& Labrou, N. E. (2009). Biochemical Journal, 422, $247-256$.

45. Kapoli, P., Axarli, I. A., Platis, D., Fragoulaki, M., Paine, M., Hemingway, J., et al. (2008). Biosensors and Bioelectronics, 24, 498-503.

46. Dixon, D. P., \& Edwards, R. (2010). Journal of Biological Chemistry, 285, 36322-36329.

47. Mukanganyama, S., Bezabih, M., Robert, M., Ngadjui, B. T., Kapche, G. F., Ngandeu, F., et al. (2011). Journal of Enzyme Inhibition and Medicinal Chemistry, 26, 460-467.

48. Dixon, D. P., \& Edwards, R. (2009). Journal of Biological Chemistry, 284, 21249-21256.

49. Oakley, A. J., Lo Bello, M., Nuccetelli, M., Mazzetti, A. P., \& Parker, M. W. (1999). Journal of Molecular Biology, 291, 913-926.

50. Mueller, L., Goodman, C. D., Silady, R. A., \& Walbot, V. (2000). Plant Physiology, 123, 1561-1570.

51. Axarli, I. A., Rigden, D. J., \& Labrou, N. E. (2004). Biochemical Journal, 382, 885-893. 